\title{
Mobile Business Intelligence Acceptance Model for Organisational Decision Making
}

\author{
Lim Yee Fang, Nurulhuda Firdaus Mohd Azmi, Yazriwati Yahya, Haslina Sarkan, Nilam Nur Amir \\ Sjarif, Suriayati Chuprat \\ Advanced Informatics Department, Razak Faculty of Technology and Informatics, \\ Universiti Teknologi Malaysia, Kuala Lumpur, Malaysia
}

\section{Article Info \\ Article history: \\ Received Aug 19, 2018 \\ Revised Oct 26, 2018 \\ Accepted Nov 15, 2018}

\section{Keywords:}

Business intelligence

Mobile BI acceptance model

Mobile business intelligence

Organizational decision making

\begin{abstract}
Mobile Business Intelligence (BI) is the ability to access BI-related data such as key performance indicators (KPIs), business metric and dashboard through mobile device. Mobile BI addresses the use-case of remote or mobile workers that need on-demand access to business-critical data. User acceptance on mobile BI is an essential in order to identify which factors influence the user acceptance of mobile BI application. Research on mobile $\mathrm{BI}$ acceptance model on organizational decision-making is limited due to the novelty of mobile BI as newly emerged innovation. In order to answer gap of the adoption of mobile BI in organizational decision-making, this paper reviews the existing works on mobile BI Acceptance Model for organizational decision-making. Two user acceptance models which are Technology Acceptance Model and Technology Acceptance Model for Mobile Services will be review. Realizing the essential of strategic organizational decision-making in determining success of organizations, the potential of mobile BI in decision-making need to be explore. Since mobile BI still in its infancy, there is a need to study user acceptance and usage behavior on mobile BI in organizational decision-making. There is still opportunity for further investigate the impact of mobile BI on organizational decision-making.
\end{abstract}

Copyright @ 2018 Institute of Advanced Engineering and Science. All rights reserved.

Corresponding Author:

Lim Yee Fang,

Advanced Informatics Department, Razak Faculty of Technology and Informatics

Universiti Teknologi Malaysia, Kuala Lumpur, Malaysia

Email: yeefanglim@gmail.com

\section{INTRODUCTION}

The concept of mobile Business Intelligence (BI) is introduced at early 1990s where the usage of mobile phone prevalent in society. However, the concept was not embraced by users due to technology and culture barrier at that time [1] until the advent of smart devices such as smartphone and tablet draw the attention of people towards the advantages of mobile BI [2].

The emergence of new technologies and tremendous growth in mobile industry started a new employee-driven IT revolution among organization [3]. Computer based data management and analysis tools are used by organizations to reveal trends and patterns hidden in their huge operational databases environment. Thus, there is need of tools to assist useful information extraction from the rapidly growing volumes of digital data [4].

Realizing big data is vital for organization to survive in this digital age, many organizations have turn to mobile BI in order to enhance their operations and gain a competitive advantage. In this regards, data become a strategic asset which drives decision-making processes in an organization. The potential of mobile BI which integrated data warehousing and BI solutions can be seen as businesses now are dependable on the power of Internet and mobile technologies for daily operations [4]. In response to new business needs where 
updated and real-time information retrieval anytime anywhere, mobile BI provides access for quick and better decision-making [1-2]. Mobile BI enables business agility where dynamic and quick decisions are made possible based on real-time data and the promised standardization [4]. Greater competitive advantage can be achieved with improved business information access and analytic via mobile BI [5].

Recent research in mobile BI includes user acceptance of mobile BI [6], framework for mobile BI deployment [7-9], architecture of mobile BI tool [10], mobile BI state-of-the-art [11-12,1] and mobile BI application development [5]. Moreover, some existing work on mobile BI emphasized on organizing vison of mobile BI [13]. However, research on mobile BI acceptance model on organizational decision-making is limited due to the novelty of mobile BI as newly emerged innovation [13].

In order to answer the gap of the adoption of mobile BI in organizational decision-making, this paper reviews the existing works on mobile BI Acceptance Model for organizational decision-making. Two user acceptance models which are Technology Acceptance Model and Technology Acceptance Model for Mobile Services will be review. This paper is organized by firstly presenting the fundamental concept of BI, mobile BI and organizational decision-making in Section 2. Next, Section 3 will further describe about the review on mobile BI acceptance model for organizational decision-making which including discussion on user acceptance, technology acceptance model and technology acceptance model for mobile services. Later, it will further discuss the proposed study on mobile BI user acceptance and usage behavior in organizational decision-making. Finally, Section 4 will conclude the review and present the future work.

\section{THE FUNDAMENTAL CONCEPT}

This section will briefly describe the fundamental concept about BI, mobile business intelligence and organizational decision-making. The purpose of the description is to have an overview of this domain knowledge and to identify their relationship towards the review on mobile BI acceptance model for organizational decision making.

\subsection{Business Intelligence (BI)}

Business Intelligence (BI) remains high ranked searched terms on gartner.com and continues as a topic of interest for researchers [14]. The term "Business Intelligence" was coined by Howard Dressner, Gartner Group's analyst in early 1990s [15] with definition "BI is concepts and methods to improve business decision making by using fact-based support systems". According to Gartner's IT Glossary (2017), "Business intelligence (BI) is an umbrella term that includes the applications, infrastructure and tools, and best practices that enable access to and analysis of information to improve and optimize decisions and performance." While for BI systems, Negash [16] presented it as "combine data gathering, data storage, and knowledge management with analytical tools to present complex internal and competitive information to planners and decision makers." This implies that BI systems facilitate decision-making by improve the timeliness and quality of inputs to the decision process with actionable information delivered at the right time, at the right location, and in the right form.

To combine the nature of BI in decision-making and technical, Işık et. al [14] refer BI as "a system comprised of both technical and organizational elements that presents its users with historical information for analysis to enable effective decision making and management support, with the overall purpose of increasing organizational performance". This has already emphasized by Gangadharan and Swami [17] which describe BI as a product of in-depth analysis of large amounts of business data which include database, applications technologies and analysis practices. From the definition proposed, to summarize, the definition of BI can be viewed in three different views; the process or management view, the technological view, and the product view.

Alongside with rapidly increasing volume, velocity, and variety of data generated, organizations are struggling to find ways to better make use of data. Consequently, BI become top ranked applications suggested by senior executives to be implement as organizations recognized the value of corporate data and information as organization's competitive advantage [18]. BI provides critical insight that helps organizations make informed decisions by scrutinize every aspect of business operations [17]. Brockmann et al. [6] pointed that BI integrates a variety of methodologies, techniques, and tools to turn data into information. BI research topics are wide in range, where it involves the research area of artificial intelligence, enterprise-wide information system, decision-making, systems implementation and competitive strategies. Technically, BI is broad and encompasses knowledge management, enterprise resource planning, decision support systems and data mining [17]. Deployment of BI in mobile devices should be considered when defining requirements for BI solutions. 


\subsection{Mobile Business Intelligence}

In the advent of portable ICT, mobile devices are increasingly deployed in activities which require human mobility [19]. The general factor for organizations to deploy mobile devices is to facilitate real-time information management and to improve the productivity of mobile workforce [19]. Moreover, the need for intelligent business information in real time envisioned mobile BI [10]. Gangadharan and Swami [17] stated that decisions made at all organizational levels and supporting analytic tools make up a big population which making the user acceptance considerable issue for mobile BI vendors.

BI technologies and concepts has evolved from DBMS-based with structured content which known as Business Intelligence \& Analytics (BI\&A) 1.0 to Web-based BI\&A 2.0 till the emerging of BI\&A 3.0 which emphasize on the analysis of mobile and sensor-based content [20]. The evolution enables shifting paradigm to integrate BI system into mobile device [21]. Brodzinski et al. [11] highlighted that mobile BI is the latest frontier to drive demand among organizations. Generally, mobile BI is using the same concept as traditional BI which uses mobile devices such as smartphones and tablets as a mean to deliver the representation of the data instead of desktop application [21]. Mobile BI presents data in the form of dashboards and visualization, interactive reporting, analysis, data exploration or reporting instead of an independent document where it designed specifically for handheld users.

Various definitions of mobile BI are available in literature. Verkooij and Spruit [22] defined mobile BI as "capability that enables the mobile workforce to gain business insights through information analysis using applications optimized for mobile devices." Whereas Stipić \& Bronzin [1] defined mobile BI as "a procedure in which data critical for making decisions is made available to end users in appropriate applications and devices that can be in any way considered mobile. This allows users to make their decisions much faster and more accurately." Similar definition has been stated by Kashora [23] that "mobile business intelligence is a procedure in which data critical for making decisions is made available to end users in appropriate applications and mobile devices such as smartphones and Tablet-PCs."

Sajjad et al. [10] stated that mobile BI approach is to take the front end view of BI onto mobile devices. Traditional BI systems deployed in local servers cannot provide real-time, accurate and comprehensive information and knowledge [24]. The demand from mobile for updated information with combination of real time data integration requires a necessity for mobile BI [12]. As a solution for remote data retrieval, mobile BI introduces a new way of delivering via mobile devices [13]. Ubiquitous remote access of mobile BI reduces the limitation of executive management staffs to their desks and office-based PCs make the traditional executive workspace obsolete.

There are various mobile BI which offer variety functionalities in the market. For instance, BusinessObjects Mobile allows viewing and manipulating reports from BusinessObjects XI via mobile devices such as Blackberry or Windows Mobile; Cognos Go! Mobile offers wireless access to Cognos BI data via a mobile client and SAP's offered mobile BI with capability to publish information to an intranet portal or mobile device.

\subsection{Organizational Decision Making}

Decision-making is essential in organization management. It is the most frequently occurring activity that individuals engaged in organizational position. Difficulties in making decisions about changes is a norm as human often fall prey to common fallacies, biases, and other decision-making errors. The lack of explicit objectives of change and criteria for prioritizing different policy options makes it problematic for impact assessments implementation [21].

Decision-making process is continuous and indispensable component of managing any organization or business activities. Strategic decisions derived from decision-making process are significant to an organization's success in long-term. It is noted that decision-making needs the right kind of information, the complete information and the ability to synthesize and make sense of the information in an organizational context. A strategic decision is designed to effectively match an organization's capabilities and resources with opportunities and threats in its environment [25]. Consequently, successful decision results in the goals achievement of organization within the time, cost, technological and cognitive constraints [25].

\section{MOBILE BI ACCEPTANCE MODEL FOR ORGANIZATIONAL DECISION-MAKING}

To see the relationship of user acceptance on mobile BI and organizational decision-making, there is a need to examine mobile BI initiatives drivers. The predominant pressures driving mobile BI initiatives are showed in Figure 1 as reported in Information Week [26]. From Figure 1, two out of five pressures stated are related to decision-making which are the need to speed decision-making and the need to deliver real-time BIdirectional data access where and when decisions are made. This shows that the main driver for mobile BI initiative in organizations is the need to make fast and efficient decisions. 
Realizing the essential of strategic organizational decision-making in determining success of organizations, the potential of mobile BI in decision-making need to be explore. Since mobile BI still in its infancy, there is a need to study user acceptance and usage behavior on mobile BI in organizational decisionmaking. The Technology Acceptance Model (TAM) and Technology Acceptance Model for Mobile Services (TAMMS) are identified as the primary theoretical framework of reference in the process of formulating mobile BI acceptance model for organizational decision-making. We discuss the difference between these two models below.

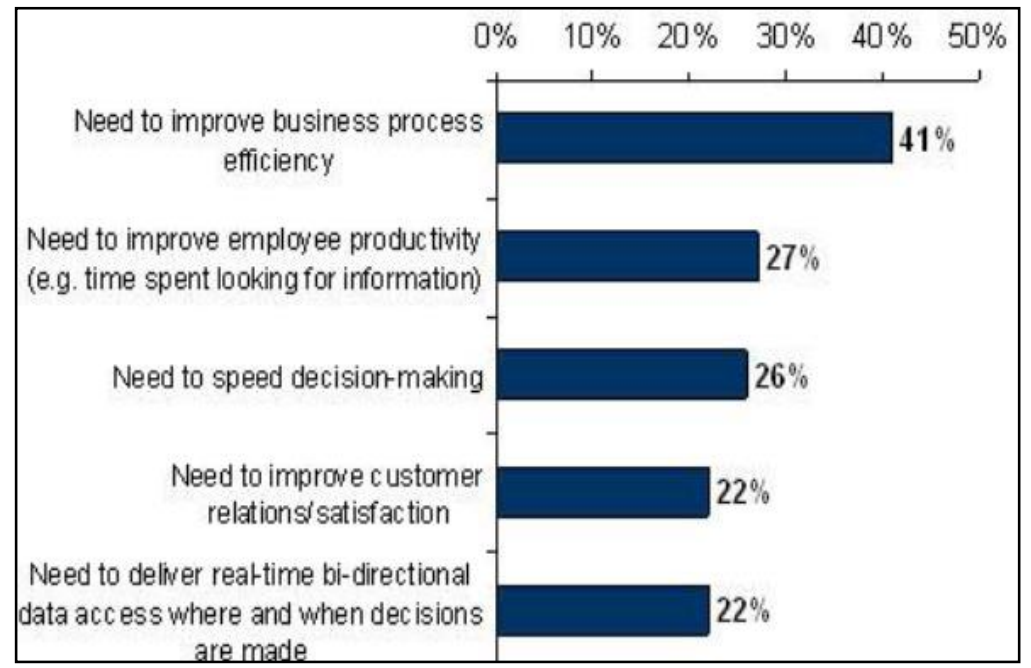

Figure 1. Top pressures driving mobile BI initiatives [26]

\subsection{Technology Acceptance Model for Mobile Services (TAMMS)}

Technology Acceptance Model (TAM) is known as one of the widely applied and adopted user acceptance models in explaining the concept of technology adoption [27]. TAM was fundamentally designed as extension of Fishbein and Ajzen's Theory of Reasoned Action (TRA) by Davis [28]. TAM illustrated perceived usefulness and perceived ease of use as important factors in determining user attitude towards new technology acceptance. TAM is primarily used to predict the individual adoption and usage of new technologies within a business environment [29]. The TAM model is illustrated as in Figure 2.

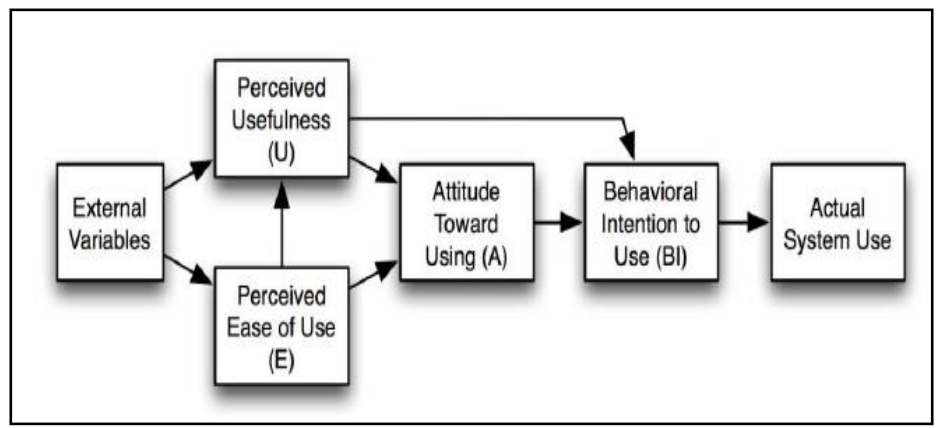

Figure 2. Technology Acceptance Model (TAM) [27]

The need to explore on the adoption and acceptance of mobile services as the ubiquity of mobile devices and services is the fact addressed by Phan \& Daim [27]. Hence, Technology Acceptance Model for Mobile Services (TAMMS) is created as a specific model that addressed issues on adoption of mobile services. Figure 3 shows the TAMMS with the refinements to the original TAM for better understanding. 


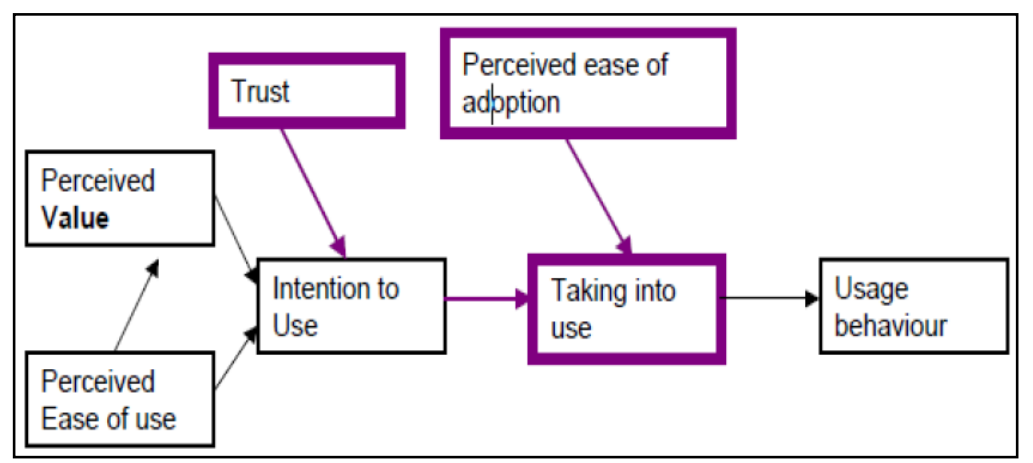

Figure 3. Technology Acceptance Model for Mobile Services (TAMMS) [30]

In context of mobile BI acceptance, Brodzinski et al. [11] stressed the importance to integrate mobile BI solution with enterprise BI solution in order to build trust and acceptance of mobile BI. Moreover, they [11] mentioned that iPhone is the first mobile device enabled acceptable mobile BI experience and the acceptance of mobile BI is facilitated by the released of the larger screen iPad and tablets. In addition, the common success factors of BI systems and mobile BI are up-to-date data, the use of dashboards to monitor key metrics and delivering fast response times as mentioned by Brockmann et al. [6].

\subsection{Proposing the Mobile BI Acceptance Model for Organisational Decision Making}

From the review presented, thus, the study propose mobile BI acceptance model which help to forecast acceptability thus, enhance organizational decision-making based on usage behavior. The findings of the study is aim to contribute onto the generalize model which applicable to worldwide organizations. The research hypothesis of the proposed study is as follow:

"The enhancement of the acceptance model of mobile business intelligence in organizational decisionmaking can improve the speed of decision making and business process efficiency."

Therefore, the main research questions derives from the proposed study is:

"What are the factors influencing user acceptance and usage behavior on mobile BI in organizational decision-making?"

Sub research questions derives from the main research question, are identified as below:

a. What are the factors initiated mobile BI in organizational decision-making?

b. What are the existing research relating to mobile BI and BI technologies as well as the adoption and usage within context of organizational decision-making?

c. How the mobile BI acceptance model can be develop for organizational decision-making using the existing Technology Acceptance Models?

d. How to evaluate the acceptance model for organizational decision-making?

A quantitative research methodology will be implemented in this study, in order to examine the relationship proposed by the model and the phenomena of user acceptance, through the collection of numerical data. Structured questionnaire will be developing as an instrument to collect information on user perception of a particular mobile BI and how the perception translates into mobile BI use. The focus was to identify if the variables, Perceived Usefulness (PU) and Perceived Ease of Use (PEOU) had a positive correlation with Attitude towards Using (ATU) and Intention to Use (ITU). This was done through an analysis of the various correlations, and frequencies. The questionnaire is planned to include those items towards using mobile BI. All items required five-point Likert-style responses ranging from 1= "Strongly Disagree" to 5= "Strongly Agree". Later the analysis will include various correlations, and frequencies to test the model on data collected, and emphasis was also added to the demographical variables of: age, gender, division and experience with the Business Intelligence tool.

This study will target company workers who accountable as organization decision-maker particularly those who hold executive or management positions as our research setting. Since the study will emphasized organizational decision-making supported with mobile BI. The respondents for this study will only include mobile BI users with installed mobile BI software in their mobile devices (smartphone or tablets). To be more specific, respondents will be asked to evaluate their current usage of mobile BI and the functionalities of mobile BI in supporting decision-making, as well as to predict future mobile BI usage related with their roles and responsibilities. 
A sample size of 250 users will be identified using convenient sampling. Convenient sampling is chosen due to the availability of respondents, quickness within which data could be gathered and the cost effectiveness of sampling method [31]. In order to test whether the sample would be suitable a Kaiser-MeyerOlkin (KMO) test is planned to conduct. The KMO test is a measure of how suitable data is for factor analysis [32]. The frequency analysis, descriptive statistics, reliability and internal consistency of the selected constructs as well as correlations between constructs, and linear regression will be used to analyze the data.

\section{CONCLUSION}

This paper reviews the existing works on mobile BI Acceptance Model for organizational decisionmaking. The fundamental concept of business intelligence, mobile business intelligence and organizational decision-making is discussed to have an understanding of the concept. Two user acceptance models which are Technology Acceptance Model and Technology Acceptance Model for Mobile Services is reviewed and is identified as the primary theoretical framework of reference in the process of formulating mobile BI acceptance model for organizational decision-making. With the continuous growth of mobile devices and technologies and the great potential of mobile BI in organizational decision-making, it shows that user acceptance and usage behavior are important aspects in determining BI success in organization. Nevertheless, the proposed study will makes an important contribution to theory and practice because there is lack of studies conducted to address the issue of mobile BI acceptance and usage behavior in the context of organizational decision-making. There is still opportunity for further investigate the impact of mobile BI on organizational decision-making.

\section{ACKNOWLEDGEMENT}

The athours would like to acknowledge Razak Faculty of Technology and Informatics, Universiti Teknologi Malaysia (UTM) for giving the oppurtanity in conducting the studies.

\section{REFERENCES}

[1] Stipić A, Bronzin T. Mobile BI: The Past, the Present and the Future. IEEE InMIPRO, Proceedings of the 34th International Convention. 2011:1560-1564.

[2] Tona O, Carlsson SA. The Organizing Vision of Mobile Business Intelligence. InECIS 2013:114.

[3] Harris J, Ives B, Junglas I. IT consumerization: When gadgets turn into enterprise IT tools. MIS Quarterly Executive. 2012;11:3

[4] Airinei, Dinu, and Daniel Homocianu. The mobile business intelligence challenge. (2010).

[5] Ramamoorthy, S.L. and Bhogal, J., Developing a Mobile Business Intelligence Application. In Eighth International Conference IEEE Complex, Intelligent and Software Intensive Systems (CISIS), 2014; 392-397.

[6] Brockmann, T., Stieglitz, S., Kmieciak, J., \& Diederich, S. User acceptance of mobile business intelligence services. In IEEE 15th International Conference on Network-Based Information Systems (NBiS), 2012; 861-866.

[7] Adeyelure, T. S., Kalema, B. M., \& Bwalya, K. J. Development of Mobile Business Intelligence framework for small and medium enterprises in developing countries: Case study of South Africa and Nigeria. In IEEE 4th International Symposium on Computational and Business Intelligence (ISCBI), 2016; 11-14.

[8] Verkooij, K., \& Spruit, M. Mobile business intelligence: key considerations for implementations projects. Journal of Computer Information Systems, 2013; 54(1), 23-33.

[9] Zhu, X., \& Huang, Y. A Framework for Mobile Business Intelligence Based on $3 G$ Communication Environment. In Advances in Future Computer and Control Systems. Springer, Berlin, Heidelberg, 2012; 75-81.

[10] Sajjad, B., Mir, A., Khawar, A., Bashir, F., \& Tariq, A. An open source service oriented mobile business intelligence tool $(M B I T)$. In IEEE International Conference on Information and Communication Technologies (ICICT'09), 2009; 235-240.

[11] Brodzinski, J., Crable, E., Ariyachandra, T., \& Frolick, M. Mobile business intelligence. International Journal of Business Intelligence Research (IJBIR), 2013; 4(2), 54-66.

[12] Panian, Z. Making Businesses Work Smarter with Mobile Business Intelligence. World Academy of Science, Engineering and Technology, International Journal of Social, Behavioral, Educational, Economic, Business and Industrial Engineering, 2012; 6(8), 2011-2016.

[13] Tona, O., \& Carlsson, S. A. The Organizing Vision of Mobile Business Intelligence. In ECIS, 2013; 114

[14] IşıK, Ö., Jones, M. C., \& Sidorova, A. Business intelligence success: The roles of BI capabilities and decision environments. Information \& Management, 2013; 50(1), 13-23.

[15] Watson, H. J., \& Wixom, B. H. The current state of business intelligence. Computer, 2007; 40(9).

[16] Negash, S. Business intelligence. Communications of the association for information systems, 2004; 13(1), 15.

[17] Gangadharan, G. R., \& Swami, S. N. Business intelligence systems: design and implementation strategies. In IEEE 26th International Conference on Information Technology Interfaces, 2004, 2004; 139-144.

[18] Luftman, J., \& Ben-Zvi, T. Key issues for IT executives 2010: judicious IT investments continue post-recession, 2010.

Mobile Business Intelligence Acceptance Model for Organisational Decision Making (Lim Yee Fang) 
[19] Wiredu, G. O.User appropriation of mobile technologies: Motives, conditions and design properties. Information and Organization, 2007; 17(2), 110-129.

[20] Chen, H., Chiang, R. H., \& Storey, V. C. Business intelligence and analytics: from big data to big impact. MIS quarterly, 2012; 1165-1188.

[21] Pratomo, I., \& Chelong, K. Decision Making in Mobile Business Intelligence: An Individual Cognitive Fit Perspective, 2016.

[22] Verkooij, K., \& Spruit, M. Mobile business intelligence: key considerations for implementations projects. Journal of Computer Information Systems, 2013; 54(1), 23-33.

[23] Kashora, Kudzai. Leveraging mobile business intelligence to create strategic business value. PhD diss., University of Cape Town; 2014.

[24] Zhu, X., \& Huang, Y. (2012). A Framework for Mobile Business Intelligence Based on $3 G$ Communication Environment. In Advances in Future Computer and Control Systems, 2012; 75-81. Springer, Berlin, Heidelberg.

[25] Harrison, E. F., \& Pelletier, M. A. Levels of strategic decision success. Management Decision, 2000; 38(2), 107118.

[26] Hatch, D. Mobile business intelligence: Best-in-Class secrets to success. Information Week, 2008; 11(12), 10.

[27] Phan, K., \& Daim, T. U. Exploring technology acceptance for mobile services. Journal of Industrial Engineering and Management, 2011

[28] Davis, F. D. A. Technology acceptance model for empirically testing new end-user information systems: Theory and results, Doctoral dissertation, Massachusetts Institute of Technology, 1985.

[29] Venkatesh, V., Morris, M. G., Davis, G. B., \& Davis, F. D. User acceptance of information technology: Toward a unified view. MIS quarterly, 2003; 425-478.

[30] Kaasinen, E. User acceptance of mobile services: Value, ease of use, trust and ease of adoption, 2005.

[31] Schnall, A. H., Wolkin, A., \& Nakata, N. Methods: Questionnaire Development and Interviewing Techniques. In Disaster Epidemiology, 2018; 101-108.

[32] Williams, B., Onsman, A., \& Brown, T.Exploratory factor analysis: A five-step guide for novices. Australasian Journal of Paramedicine, 2010; 8(3). 